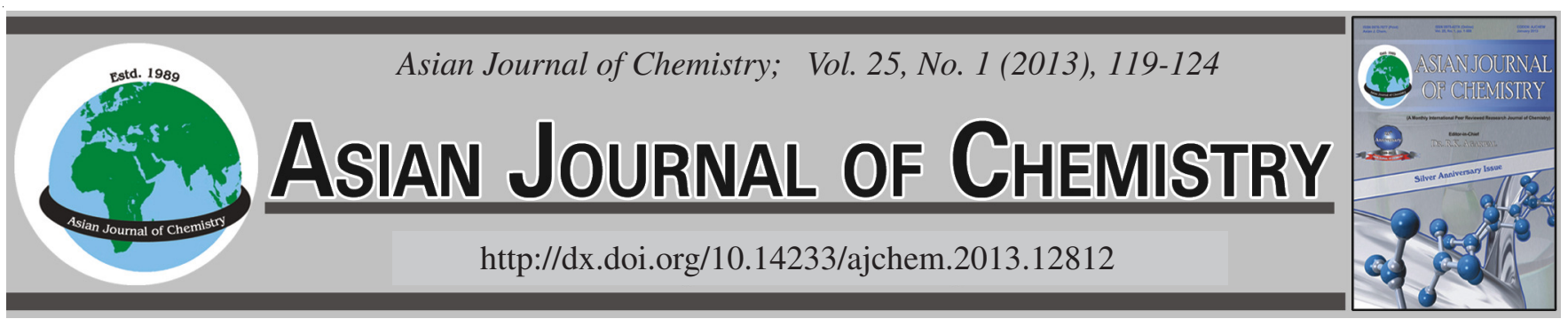

\title{
Electrochemical Determination of Ascorbic Acid Using Modified Glassy Carbon Electrode by Multiwall Carbon Nanotube-Nafion in Chloroacetic Acid Media
}

\author{
Meissam Noroozifar ${ }^{1, *}$, Mozhgan Khorasani-Motlagh ${ }^{2}$ and Hamed Tavakkoli ${ }^{1}$
}

${ }^{1}$ Analytical Research Laboratory, Department of Chemistry, University of Sistan and Baluchestan, Zahedan, P.O. Box 98155-147, Iran ${ }^{2}$ Inorganic Research Laboratory, Department of Chemistry, University of Sistan and Baluchestan, Zahedan, Iran

*Corresponding author: Fax: +98 541 2446888; Tel: +98 541 2446565, E-mail: mnoroozifar@ chem.usb.ac.ir

\begin{abstract}
In this study, ascorbic acid was simply determined at lower potential compared to bare glassy carbon by replacement phosphate buffer solution with chloroacetate buffer solution at surface of modified glassy carbon electrode. A film of Nafion with multi-walled carbon nanotubes (MWCNT) was prepared by rapidly casting solution onto the surface of a glassy carbon electrode and drying under room temperature. For MWCNT-Nafion film was not observed any peaks in the used potential range in phosphate buffer solution. However, by replacing phosphate buffer solution with chloroacetate buffer solution, due to interaction between nafion film and component of chloroacetate buffer solution in a positive scan, an oxidation peak was obtained at about $0.442 \mathrm{~V}$ and at a reversal scan a reduction peak was observed at about $0.282 \mathrm{~V}$. Scan rate, $\mathrm{pH}$ and interference effects for the determination of ascorbic acid were studied. It was found that glassy carbon electrode/MWCNT-Nafion in chloroacetate buffer solution $\mathrm{pH}=2$, increase significantly the cyclic voltammogram peak currents as well as a decreasing the oxidation overpotentials of ascorbic acid compared to bare glassy carbon. A linear range between $5.0 \times 10^{-5} \mathrm{~mol} / \mathrm{L}$ and $2.32 \times 10^{-2} \mathrm{~mol} / \mathrm{L}$ and a detection limit $(3 \sigma) 1.2 \times 10^{-5} \mathrm{~mol} / \mathrm{L}$ was obtained for modified electrode. Finally, the novel modified electrode was successfully applied to the determination of ascorbic acid in pharmaceuticals and foods in acetate medium.
\end{abstract}

Key Words: Electrode modification, Nafion, Multi-walled carbon nanotubes, Chloroacetate buffer, Ascorbic acid, Electrocatalytic determination.

\section{INTRODUCTION}

Ascorbic acid (AA) is used in large scale as an antioxidant in food, animal feed, beverages, pharmaceutical formulations and cosmetic applications. Ascorbic acid is the major soluble antioxidant found in plants and is also an essential component of human nutrition ${ }^{1}$. In addition, ascorbate is important for neuronal maturation and function, as well as for protection of the brain against oxidant stress, is well supported by previous work ${ }^{2}$. In view of the great importance and wide use of ascorbic acid, numerous analytical techniques have been proposed for its determination in different matrices and at different levels. These include flow injection (FI) analysis ${ }^{3}$, chromatography ${ }^{4}$, spectrophotometry $^{5,6}$ and voltammetry ${ }^{7-9}$. Ascorbic acid can be measured using voltammetry methods in order to gain the advantages of high sensitivity and selectivity.

Recently, polymer films modified electrodes have been receiving extensive interest due to their wide applications in the fields of chemical sensors and biosensors. Polymermodified electrodes have many advantages in the detection of analytes because of its high selectivity, sensitivity and homogeneity in electrochemical deposition, strong adherence to electrode surface and chemical stability of the film ${ }^{10}$. Glassy carbon electrodes have been widely used for modification ${ }^{11,12}$ compared with metal electrodes due to its biocompatibility with tissue, having low residual current over a wide potential range and minimal propensity to show a deteriorated response as a result of electrode fouling ${ }^{13}$.

Nanotubes, the last in the focus of scientists in a series of all carbon materials discovered over the last several decades are the most interesting and have the greatest potential ${ }^{14}$. A huge, cylindrical surface area and graphene sheet carbon nanotube have special properties, such as high electrical conductivity, chemical stability and catalyst support, which are useful for an analytical biosensor ${ }^{15}$. Carbon nanotube-modified electrodes promote electron transfer due to their conductivity and mechanical properties. Composites of a conducting polymer and carbon nanotubes show synergistic affects and has been made for different applications ${ }^{16}$. Wrapping carbon nanotubes by polymeric chains is now a new approach for achieving the solubility without any considerable impairment their physical, chemical and electrochemical properties ${ }^{17}$. 
Composite materials based on solubilizing carbon nanotubes with various polymers especially Nafion and chitosan have been reported ${ }^{18-20}$.

Nafion is an anionic sulfonated fluorocopolymer of tetrafluoroethylene (Teflon) and perfluoro-3,6-dioxa-4-methyl7-octene-sulfonic acid. Nafion is not only like Teflon highly resistant to chemical attack, it also exhibits highly selective absorption and transfer of compounds. It has hydrophobic $\left(-\mathrm{CF}_{2}-\mathrm{CF}_{2}-\right)$ and hydrophilic $\left(-\mathrm{SO}_{3} \mathrm{H}\right)$ regions in its polymeric structure (Fig. 1) and its superacidity is attributed to the electron-withdrawing effect of the perfluorocarbon chain acting on the sulfonic acid group. Nafion is able to catalyze various reactions, such as alkylation, disproportionation and esterification. Moreover, it has the unique ion exchange, discriminative, good electrical conductivity, good biocompatibility, excellent film forming and adhesion ability, high chemical stability and ability to resist interferences from anions and biological macromolecules, which make it a good matrix for bimolecular immobilization $^{21}$. In consequence of this abilities modified electrodes base on Nafion-carbon nanotube have been investigated intensively for analytical application a variety of bimoleculars such as ascorbic acid, dopamine, uric acid, methanol and others ${ }^{22-25}$ and applied for the voltammetric sensing in the electrochemical sensors and biosensors.

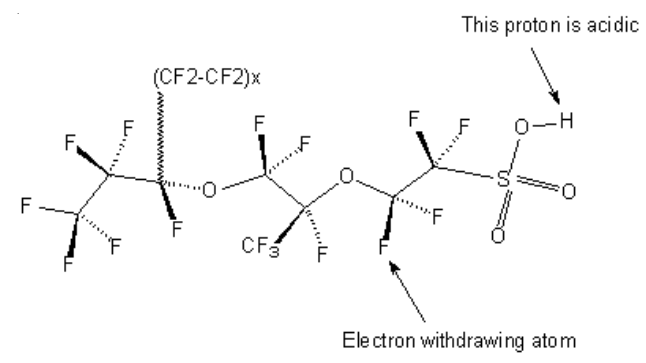

Fig. 1. Chemical structures of Nafion

Herein, this work includes the fabrication of a new modified glassy carbon electrode based on multiwalled carbon nanotube dispersed in Nafion for the determination of ascorbic acid. The electrochemical behaviour of this modified electrode has been studied in chloroacetate acid buffer (CAAB) solutions $\mathrm{pH}=2$. Analytical performance of this sensor for determination of this analyte was evaluated and showed satisfactory results. Finally, this sensor has been used for the determination of this compound in pharmaceuticals and foods successfully. Easy electrode preparation and low detection limits for ascorbic acid was obtained due to the high electrocatalytic properties of MWCNT-Nafion in acidic media. It was also successfully used for the determination of ascorbic acid in presence of the common interference compounds.

\section{EXPERIMENTAL}

Ascorbic acid was purchased from Fluka-Sigma and was used as received. Multiwall carbon nanotubes (MWCNT), with nanotube diameters, $\mathrm{OD}=20-30 \mathrm{~nm}$, wall thickness $=1-2 \mathrm{~nm}$, length $=0.5-2 \mu \mathrm{m}$ and purity of $>95 \%$ was purchased from Aldrich. A $2.5 \%$ Nafion solution (Aldrich, EW, 1100, dissolved in a lower aliphatic alcohol and water) was used for preparing MWCNT-Nafion film. $\mathrm{H}_{3} \mathrm{PO}_{4}, \mathrm{NaH}_{2} \mathrm{PO}_{4}$ and $\mathrm{NaOH}$, were purchased from Merck. Chloroacetic acid $\left(p \mathrm{~K}_{\alpha}=2.87\right)$ was used for preparation of buffer solutions between 1.8 and 3.8, it was prepared by adjusting it to desire $\mathrm{pH}$ with $0.1 \mathrm{~mol} \mathrm{~L}^{-1}$ $\mathrm{NaOH}$ solution. In a same way for acetic acid buffer solution, acetic acid $(p K \alpha=4.76)$ for $\mathrm{pH}$ between 4.0 and 5.6 was used. Phosphate buffer solutions were prepared from $\mathrm{H}_{3} \mathrm{PO}_{4}$ and $\mathrm{NaH}_{2} \mathrm{PO}_{4}\left(0.1 \mathrm{~mol} \mathrm{~L}^{-1}\right)$ and adjusted the $\mathrm{pH}$ range over 2-10 with $0.1 \mathrm{~mol} \mathrm{~L}^{-1} \mathrm{H}_{3} \mathrm{PO}_{4}$ and $\mathrm{NaOH}$ solutions. All experiments were performed under nitrogen atmosphere at room temperature. All the solutions were freshly prepared with doubly distilled water and all other chemicals used were of analytical reagent grade. Electrochemical measurements were carried out with a SAMA500 electroanalyser (SAMA Research Center, Iran). All electrochemical experiments were carried out in a conventional three-electrode cell at room temperature. A platinum electrode and a saturated calomel electrode were used as the counter and reference electrodes, respectively. A Metrohm $632 \mathrm{pH}$-meter with a Metrohm double junction glass electrode was used for monitoring $\mathrm{pH}$ adjustment.

Preparation of working electrodes: Before being modified, the glassy carbon electrode was refined successively with $0.05-\mu \mathrm{m} \mathrm{Al}_{2} \mathrm{O}_{3}$ slurry. After rinsing with doubly distilled water, it was sonicated in water and absolute ethanol for about $1 \mathrm{~min}$ each. Next, the glassy carbon electrode was transferred to the electrochemical cell for further cleaning by using cyclic voltammetry between -1.00 and $+1.00 \mathrm{~V}$ at a scan rate of 100 $\mathrm{mVs}^{-1}$ in recently prepared deoxygenated $0.5 \mathrm{~mol} \mathrm{~L}^{-1} \mathrm{H}_{2} \mathrm{SO}_{4}$ until stable cyclic voltammetric profiles were obtained. The treated electrode was dried under a nitrogen stream and used instantly for modification. After that, first make a $2.5 \%$ solution of Nafion (diluted with ethanol: doubly distilled water, 1:1) and then added $25 \mathrm{mg}$ of MWCNT and agitation with ultrasonic to give a black suspension. Then the glassy carbon electrode was smeared evenly with $6 \mu \mathrm{L}$ of a suspension solution by a micro-syringe and dried under an inafionrared lamp for $10 \mathrm{~min}$. This modified GC electrode was denoted as GC/MWCNT-Nafion. Also, the GC/Nafion electrode was prepared with the same method.

\section{RESULTS AND DISCUSSION}

Optimization of buffer solution and electrode composition: The first step of the work consisted of finding the optimum buffer solution and electrode composition. In order to decide about the optimum condition of the developed electrode, modified electrode were examined by recording cyclic voltammograms of modified electrode in different buffer solution $\left(0.1 \mathrm{~mol} \mathrm{~L}^{-1}\right)$ of the chloroacetate acid buffered solution and phosphate buffered solution. A typical cyclic voltammogram are given in Fig. 2.

Glassy carbon electrode/MWCNT-Nafion electrode did not show any anodic and cathodic peaks in phosphate buffer solutions (curve a). Based on a cyclic voltammogram for glassy carbon electrode/MWCNT-Nafion (Fig. 2, curve c), the potential of the anodic $\left(\mathrm{E}_{\mathrm{pa}}\right)$ and cathodic $\left(\mathrm{E}_{\mathrm{pc}}\right)$ peaks and the half-wave potential $\left(\mathrm{E}_{1 / 2}\right)$ are $0.442,0.282 \mathrm{~V}$ and $0.362 \mathrm{~V}$, respectively. Also, the glassy carbon electrode/Nafion electrode exhibited a pair of redox peaks and the half-wave potential $\left(\mathrm{E}_{1 / 2}\right)$ at $0.654,0.065$ and $0.360 \mathrm{~V}$ (curve b) respectively, in 
TABLE-1

ELECTROCHEMICAL DATA FOR DIFFERENT MODIFIED ELECTRODES IN BOTH CHLOROACETATE BUFFER AND PHOSPHATE BUFFER SOLUTIONS ( $v s$. SCE). SCAN RATE, $v=100 \mathrm{mV} \mathrm{s}^{-1}, \mathrm{pH}=2.0$

\begin{tabular}{|c|c|c|c|c|c|c|c|c|}
\hline \multirow{2}{*}{ Modified electrode } & \multicolumn{2}{|c|}{$E / \mathrm{V}$} & \multirow{2}{*}{$\mathrm{E}_{1 / 2} / \mathrm{V}$} & \multirow{2}{*}{$\Delta \mathrm{E}_{\mathrm{p}} / \mathrm{V}$} & \multicolumn{2}{|c|}{$\mathrm{I} / \mu \mathrm{A}$} & \multirow{2}{*}{$\mathrm{I}_{\mathrm{pa}} / \mathrm{I}_{\mathrm{pc}}$} & \multirow{2}{*}{ Buffer type } \\
\hline & $\mathrm{E}_{\mathrm{pa}}$ & $E_{p c}$ & & & $\mathrm{I}_{\mathrm{pa}}$ & $\mathrm{I}_{\mathrm{pc}}$ & & \\
\hline GCE/MWCNT-NAF & - & - & - & - & - & - & - & PBS \\
\hline GCE/NAF & 0.658 & 0.068 & 0.363 & 0.590 & 52.36 & -51.23 & 1.022 & CABS \\
\hline GCE/MWCNT-NAF & 0.442 & 0.282 & 0.362 & 0.160 & 66.55 & -65.96 & 1.009 & CABS \\
\hline
\end{tabular}

chloroacetate acid buffered solution, which can be attributed to the electron transformations of Nafion in chloroacetate acid buffered solution. A summary of electrochemical data for the modified electrodes are shown in Table-1. The increase in current value and the decrease in peak potential (curve $b$ and c) can be attributed to the electrocatalytic activity of carbon nanotube, which can mediate the electron transfer reactions. Large surface area is another important advantage of carbon nanotube that can facilitate the modification of the glassy carbon electrode/MWCNT-Nafion with biological molecules.

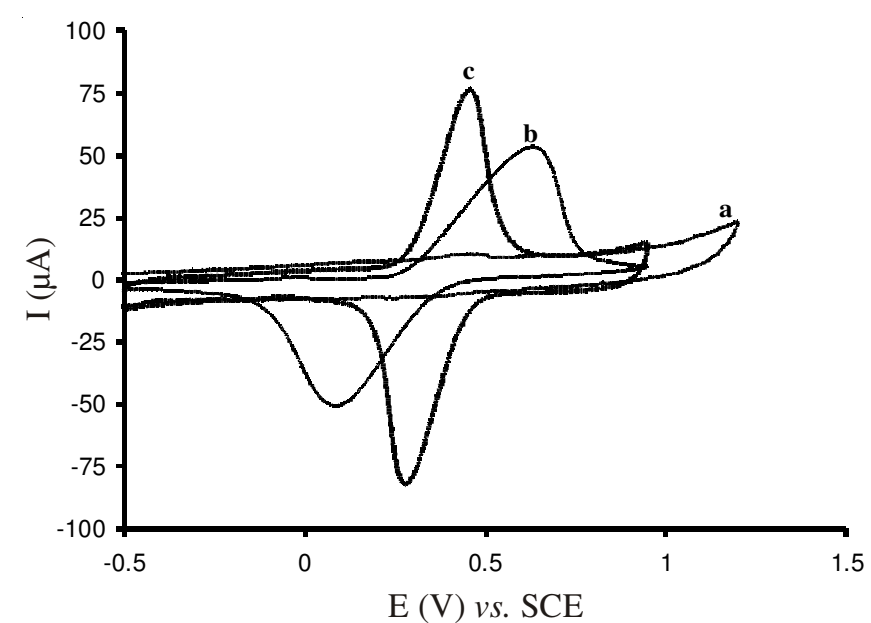

Fig. 2. Cyclic voltammograms of (a) glassy carbon electrode/MWCNTNafion in $0.1 \mathrm{~mol} \mathrm{~L}^{-1}$ phosphate buffer solution, $\mathrm{pH} 2$ (b) glassy carbon electrode/Nafion and (c) glassy carbon electrode/MWCNTNafion in $0.1 \mathrm{M}$ chloroacetate buffer solution $(\mathrm{pH}=2)$. Scan rate was $100 \mathrm{mV} \mathrm{s}^{-1}$

It was also concluded that electrochemical behaviour of glassy carbon electrode/MWCNT-Nafion was more reversible compared to glassy carbon electrode/Nafion, where Nafion was coupled with multi-wall carbon nanotube and leading to a considerable improvement in the analytical sensitivity.

The effect of the scan rate for glassy carbon electrode/ MWCNT-Nafion by using cyclic voltammetry is shown in Fig. 3A. These cyclic voltammograms were used to examine the variation of the peak current versus the sweep rate. Fig. 3A shows that the modified electrode had a chemically quasireversible redox couple in a phosphate buffer solutions $(\mathrm{pH}$ 2.0) solution and that peak currents were increased due to the cyclic voltammetric scan rate. As shown in Fig. $3 B, I_{p a}$ and $I_{p c}$ were linearly dependent on the scan rate, as expected for surface confined-redox process. The ratio of the anodic peak current $\left(\mathrm{I}_{\mathrm{pa}}\right)$ to cathodic peak current $\left(\mathrm{I}_{\mathrm{pc}}\right)$ is almost equal to unity $\left(I_{p a}: I_{p c}=1\right)$. These behaviours are consistent with a diffusionless system, reversible electron transfer process at low scan rates ${ }^{27}$.
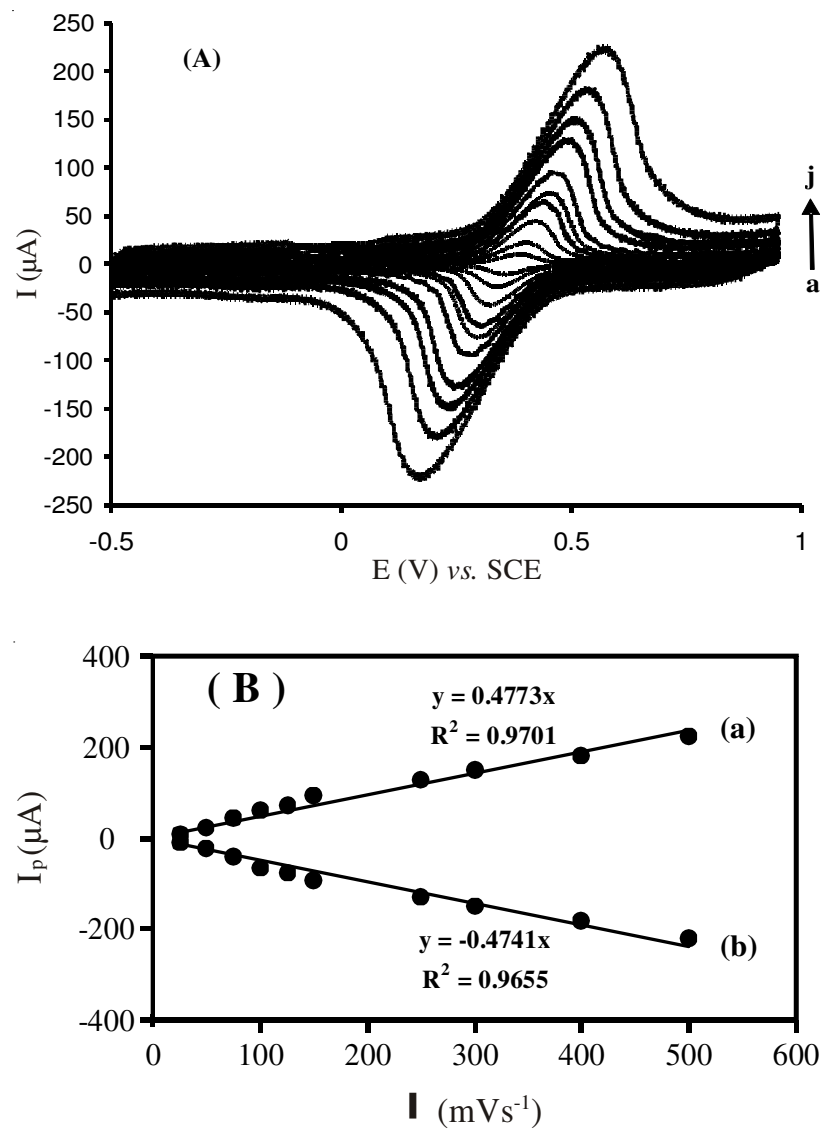

Fig. 3. (A) Cyclic voltammograms of GCE/MWCNT-/NAF in $0.1 \mathrm{~mol} \mathrm{~L}^{-1}$ CABS pH 2, at various scan rates: (a) 25; (b) 50; (c) 75; (d) 100; (e) 125; (f) 150; (g) 250; (h) 300; (i) 400; (j) 500; (B) Plots of anodic and cathodic peak currents of GCE/MWCNT-NAF $v$ s. scan rate (v) from cyclic voltammograms

Influence of pH on the film behaviour: The effect of the $\mathrm{pH}$ on the electrochemical behaviour of ascorbic acid was examined over the $\mathrm{pH}$ range from 2 to 10 at the surface of the modified electrode by cyclic voltammetry. Based on the results, the anodic peak current of glassy carbon electrode/ MWCNT-Nafion decreases with an increase in the solution $\mathrm{pH}$ until with increasing $\mathrm{pH}$, the anodic peak current was disappeared at $\mathrm{pH}$ value 6 . The cathodic peak current of glassy carbon electrode/MWCNT-Nafion also decreases slightly compared to anodic peak current with increasing pH (Fig. 4). Hence, for glassy carbon electrode/MWCNT-Nafion, the highest anodic peak current was obtained at $\mathrm{pH} 2$. It must be noted that all the anodic peak potentials for glassy carbon electrode/MWCNT-Nafion were decreased linear with increasing $\mathrm{pH}$ from 2 to 6 , showing that protons have taken part in their electrode processes ${ }^{28}$. Because of suitable peak currents, a chloroacetate acid buffered solution with $\mathrm{pH} 2$ was chosen as optimal $\mathrm{pH}$. 

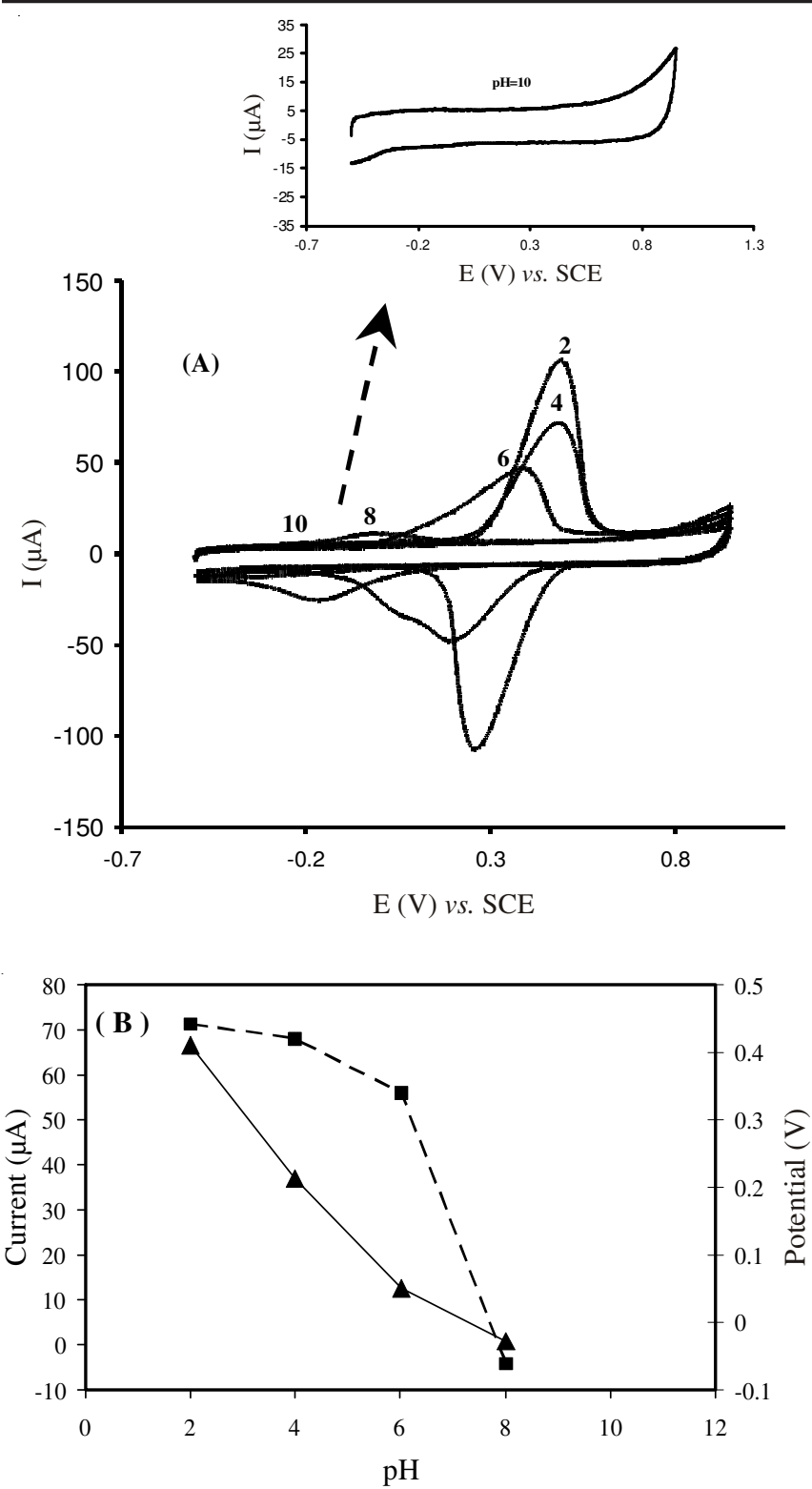

Fig. 4. (A) Cyclic voltammograms of GCE/MWCNT-NAF at various $\mathrm{pH}$ $2.0 ; 4.0 ; 6.0 ; 8.0$ and 10.0. (B) The effect of $\mathrm{pH}$ on the anodic peak current (solid line) and anodic peak potential (dash line) of GCE/ MWCNT-NAF at scan rate $100 \mathrm{mV} \mathrm{s}^{-1}$

Stability and reproducibility of the modified electrode: Prior to using glassy carbon electrode/MWCNT-Nafion for the electrocatalytic oxidation of ascorbic acid, reproducibility and stability of the modified electrode was investigated. The rate of loss of electrochemical activity for this electrode was evaluated by noting any decrease in the anodic charge (qa), in five consecutive potential scan cycles (Fig. 5). Based on obtained results, any change in the half-wave potential, $\mathrm{E}_{1 / 2}$ and any decrease in the anodic and cathodic peak currents of glassy carbon electrode/MWCNT-Nafion were not observed. The long lifetime stability of the sensor was exceptional. It was notable that after 60 days the sensor retained $97.3 \%$ of the initial sensitivity to ascorbic acid. Good response reproducibility and stability may be explained by the fact that the Nafion-chloroacetate acid buffered solution complexes are uniformly self-assembled at surface of glassy carbon electrode and unable to exit from it during potential sweep.

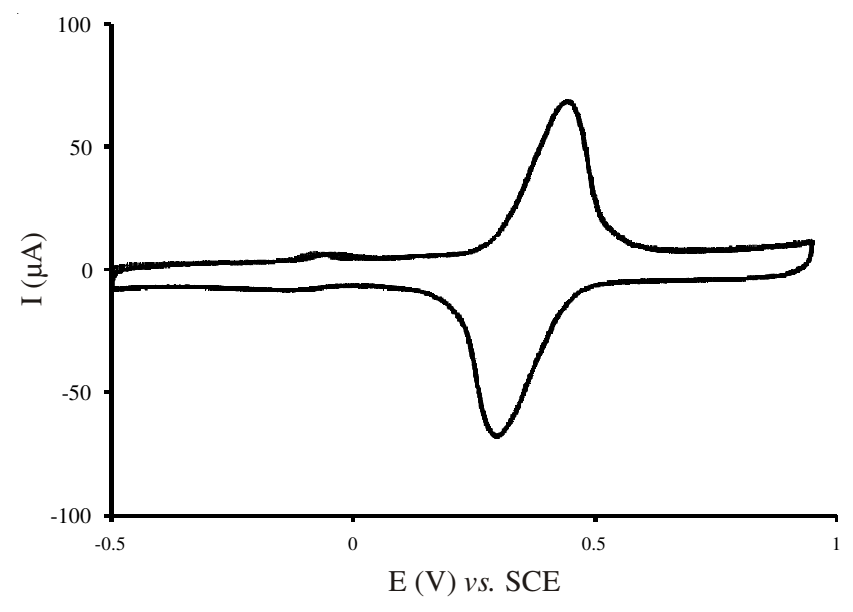

Fig. 5. Cyclic voltammograms of GCE/MWCNT/NAF in 5 consecutive potential scan cycles in CABS ( $\mathrm{pH} 2.0)$ at a scan rate of $100 \mathrm{mV} \mathrm{s}^{-1}$

Electrocatalytic oxidation of ascorbic acid at the surface of glassy carbon electrode/MWCNT-Nafion: The main objective of the present work is to determine the concentration of ascorbic acid using modified glassy carbon electrode in chloroacetate buffered solution. Fig. 6 depicts the CVs obtained for bare glassy carbon and glassy carbon electrode/ MWCNT-Nafion modified electrode in $0.1 \mathrm{M}$ chloroacetate acid buffered solution $\mathrm{pH}=2$ containing $6.9 \times 10^{-4} \mathrm{M}$ ascorbic acid. The bare glassy carbon and glassy carbon electrode/ MWCNT-Nafion electrodes showed an oxidation wave at 0.660 and $0.455 \mathrm{~V}$ (Fig. 6) and a current difference $(\Delta \mathrm{I} / \mu \mathrm{A})$ ascorbic acid, 4.5 and $34.4 \mu \mathrm{A}$ for $6.9 \times 10^{-4} \mathrm{M}$, respectively. It is shown that the cyclic voltammogram of the oxidation peak potential of ascorbic acid at the glassy carbon electrode/ MWCNT-Nafion shifted by $0.205 \mathrm{~V}$ to the negative direction compared with that bare glassy carbon electrode and the peak current at the glassy carbon electrode/MWCNT-Nafion also increased. The results indicate that the electrocatalytic activity of the modified electrode can be applied to the determination of ascorbic acid. The peak potential for the oxidation of ascorbic acid was lowered by at least $0.205 \mathrm{~V}$ compared with that obtained at an unmodified glassy carbon electrode. In contrast to bare glassy carbon electrode, when glassy carbon electrode/ MWCNT-Nafion was used as the working electrode, the detection sensitivity was improved significantly and effective increasing of the anodic peak of ascorbic acid was obtained.

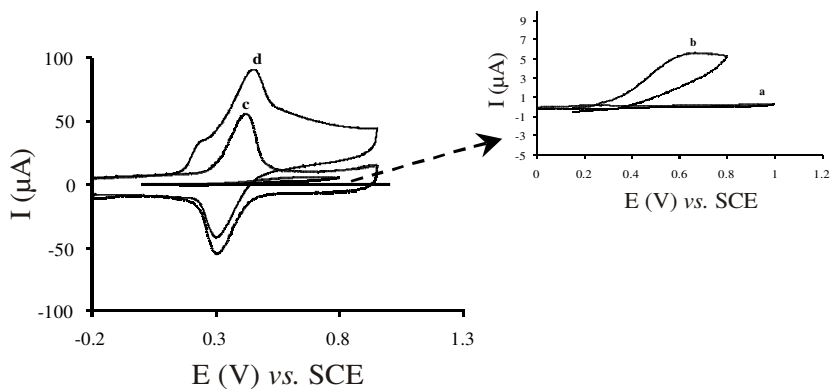

Fig. 6. Cyclic voltammograms of (a) bare glassy carbon, (b) as (a) in present of $6.9 \times 10^{-4} \mathrm{MAA}$, (c) GCE/MWCNT-NAF and (d) as (c) in present of $6.9 \times 10^{-4} \mathrm{M} \mathrm{AA}$ in CABS $(\mathrm{pH} 2.0)$ at scan rate $100 \mathrm{mV} \mathrm{s}^{-1}$

Evaluation of the proposed modified electrode: Under various optimum experimental conditions, determination of 
ascorbic acid was carried out at the potential range of 0.0 to $1.0 \mathrm{~V}$ using the cyclic voltammetry mode. Cyclic voltammograms of glassy carbon electrode/MWCNT-Nafion versus the ascorbic acid concentration are shown in Fig. 7. The ascorbic acid electro-oxidation peak was observed at the potential of about $0.445 \mathrm{~V}$ versus saturated calomel electrode. The electrocatalytic peak current of ascorbic acid oxidation at the surface of glassy carbon electrode/MWCNT-Nafion was linearly dependent on the ascorbic acid concentration. These peak currents were linear up to $0.023 \mathrm{M}$ and was described by the equation $\Delta \mathrm{I}_{(\mu \mathrm{A})}=9854.5$ [ascorbic acid] $+68.6, \mathrm{r}=0.9990$, $\mathrm{n}=16$, where $\Delta \mathrm{I}_{(\mu \mathrm{A})}$ is the difference of the oxidation peak currents glassy carbon electrode/MWCNT-Nafion before and after addition of ascorbic acid, $[\mathrm{AA}]_{(\mathrm{M})}$ is the ascorbic acid concentration, $\mathrm{r}$ is the correlation coefficient and $\mathrm{n}$ represents the number of determinations (Fig. 7). The detection limit $(3 \sigma)$ was $1.2 \times 10^{-5} \mathrm{M}$. Relative standard deviation (RSD \%) for 5 determinations of ascorbic acid with $4.6 \times 10^{-4} \mathrm{M}$ concentration was $0.6 \%$.
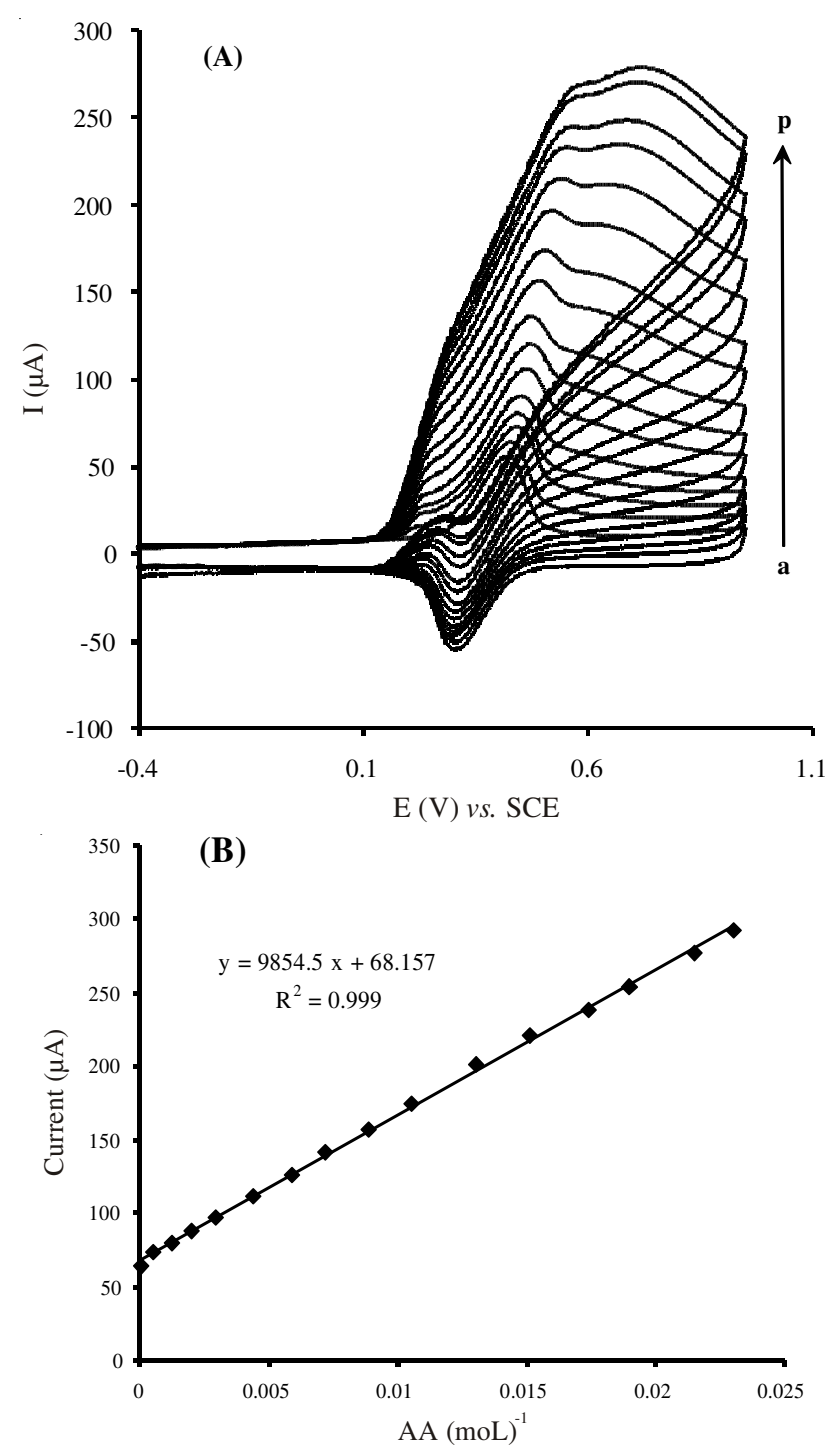

Fig. 7. (A) Cyclic voltammograms of ascorbic acid at various concentration (from a to p): $00.0 ; 0.05 ; 0.31 ; 0.69 ; 1.2 ; 1.9 ; 2.9 ; 4.4 ; 5.9 ; 7.2 ; 8.9$; $10.5 ; 13.0 ; 15.1 ; 17.4 ; 19.0 ; 21.5$ and $23.2 \mathrm{mM}$ at surface of the GCE/MWCNT/NAF. Solution conditions were $\mathrm{pH} 2.00(0.1 \mathrm{M}$ CABS), scan rate $100 \mathrm{mVs}^{-1}$. (B) Plot of $\mathrm{I}_{\mathrm{pa}} v s$. c
Interference studies: The influence of other several compounds such as maleic acid, maltose, sucrose, fructose, oxalic acid, succinic acid, tartaric acid and glucose on the electrocatalytic peak current of ascorbic acid oxidation at the surface of glassy carbon electrode/MWCNT-Nafion was examined using cyclic voltammetry. If the tolerance limit was taken as the maximum concentration of the foreign substances, which caused an approximately $5 \%$ relative error, for $4.6 \times 10^{-4}$ mol L ${ }^{-1}$ ascorbic acid. The experimental results showed that the presence of these compounds (except glucose) did not significantly influence the determination of ascorbic acid under the experimental conditions. Therefore, this result demonstrated the selectivity of this method for the voltammetric determination of ascorbic acid. The results are listed in Table- 2 .

TABLE-2

EFFECT OF DIVERSE SUBSTANCES ON THE ANALYSIS OF $4.6 \times 10^{-4} \mathrm{~mol} \mathrm{~L}^{-1}$ ASCORBIC ACID

\begin{tabular}{lc}
\hline Substance & $\begin{array}{c}\text { [Interference } \\
\text { substance]/[AA] }\end{array}$ \\
\hline Maleic acid, maltose & 1000 \\
Sucrose & 500 \\
Fructose, oxalic acid, succinic acid, tartaric acid & 100 \\
Glucose & 10 \\
\hline
\end{tabular}

Real samples: In order to demonstrate the catalytic oxidation of ascorbic acid in the real sample, we examined this ability in the voltammetric determination of ascorbic acid in some pharmaceutical preparations and foods. Orange juice and pharmaceutical samples such as ascorbic acid tablets and powder (purchased from local sources) were selected as real samples for analysis by the proposed method using the standard addition method in order to prevent any matrix effect. The results were compared with those obtained using the official iodometric titration method ${ }^{29}$. The paired $t$-test equation, applied in statistics is;

$$
\mathrm{t}=\left|\frac{\overline{\mathrm{d}} \sqrt{\mathrm{n}}}{\mathrm{s}_{\mathrm{d}}}\right|
$$

where, $\overline{\mathrm{d}}$ and sd are the mean and standard deviation respectively of $\bar{d}$ (the difference between paired values). For the pairs of values in Table-3, the mean difference, $\overline{\mathrm{d}}$, is -2.275 and the standard deviation of the differences, $\mathrm{s}_{\mathrm{d}}$, is 3.17 . The calculated $|\mathrm{t}|$ was found to be 1.44 . The critical value of $t$ (tabulated t) for $\mathrm{n}-1$ degrees of freedom (in this work 3 ) is 3.18 (P $=0.05)$. Since the calculated value of $t$ is less than this the null hypothesis is not rejected: the methods do not give significantly different results for ascorbic acid concentration ${ }^{30}$.

TABLE-3

DETERMINATION OF ASCORBIC ACID IN REAL SAMPLES USING GCE/MWCNT/NAF ELECTRODE

\begin{tabular}{lccc}
\hline Sample & $\begin{array}{c}\text { Claimed } \\
\text { preparation } \\
(\mathrm{mg})\end{array}$ & $\begin{array}{c}\text { Proposed } \\
\operatorname{method}^{\mathrm{a}} / \\
\mathrm{mg}( \pm \mathrm{SD})\end{array}$ & $\begin{array}{c}\text { Iodine } \\
\operatorname{method}^{\mathrm{a}}(\mathrm{mg}) \\
( \pm \mathrm{SD})\end{array}$ \\
\hline AA tablet & 250 per tablet & $238.2( \pm 1.5)$ & $242.5( \pm 1.7)$ \\
AA Powder & 500 per sachet & $480.2( \pm 1.6)$ & $483.9( \pm 1.9)$ \\
Baluchestan's & - & $88.2( \pm 2.4)$ & $84.9( \pm 2.1)$ \\
Orange $(100 \mathrm{~mL})$ & & & \\
\hline \multicolumn{2}{l}{ Results based on five replicate determinations per sample }
\end{tabular}




\section{Conclusion}

This work explore a simple method for determination of ascorbic acid at lower potential compared to bare glassy carbon electrode using modified glassy carbon electrode by easy changing buffer solution. The modified glassy carbon electrode with mixture of MWCNT and Nafion shows efficient electrocatalytic activity for determination of ascorbic acid in chloroacetate acid buffered solution ( $\mathrm{pH}$ 2.0). For glassy carbon electrode/MWCNT-Nafion modified electrode any peaks were not observed in the used potential range in phosphate buffer solutions. In contrast, because of interaction between Nafion film and component of chloroacetate acid buffered solution (formation a complex at surface of electrode) in a positive scan an oxidation peak was obtained at about $0.442 \mathrm{~V}$ and at a reversal scan a reduction peak was observed at about 0.282 . Modified electrode not only shifted the oxidation potential of ascorbic acid towards less positive potential (at least $0.205 \mathrm{~V}$ compared to bare glassy carbon) but also enhanced its oxidation peak. The proposed voltammetric method is a rapid, simple, strict, sensitive, suitable and selective method for routine control and can be carried out directly without any pretreatment for the determination of ascorbic acid in real samples. For study the capability of this modified electrode in the real samples, some pharmaceutical preparations and foods were used and compared with standard titrimetric method. There was no significant difference between the two methods. Very easy fabrication procedure, wide linear range, high stability and good reproducibility for repeated determination, propose this electrode as a good and attractive applicant for practical applications.

\section{REFERENCES}

S.A. Kumar, P.H. Lo and S.M. Chen, Biosens. Bioelect., 24, 518 (2008). F.E. Harrison and J.M. May, Free Radic. Biol. Med., 46, 727 (2009).

3. M. Noroozifar and M. Khorasani-Motlagh, Talanta, 61, 173 (2003).

4. A. Tai and E. Gohda, J. Chromatogr. B, 853, 214 (2007).
5. M. Noroozifar, M. Khorasani-Motlagh and A. Farahmand, Acta Chim. Slov., 51, 717 (2004).

6. M. Noroozifar and M. Khorasani-Motlagh, Turk. J. Chem., 27, 717 (2003).

7. T. Rohani and M.A. Taher, Talanta, 78, 743 (2009).

8. M. Noroozifar, M. Khorasani-Motlagh and H. Tavakkoli, Anal. Sci., 27, 929 (2011).

9. M. Khorasani-Motlagh and M. Noroozifar, Anal. Sci., 19, 1671 (2003).

10. R. Zhang, G.D. Jin, D. Chen and X.Y. Hu, Sens. Actuators B, 138, 174 (2009).

11. A.A. Ensafi, S.D.-Tehrani and B. Rezaei, J. Serb. Chem. Soc., 75, 1685 (2010).

12. S. Stevanoic, D. Tripkovic, A. Kowal, D. Minic, V.M. Jovanovic and A. Tripkovic, J. Serb. Chem. Soc., 73, 845 (2008).

13. G. Jin, F. Huang, W. Li, S. Yu, S. Zhang and J. Kong, Talanta, 74, 815 (2008).

14. S.N. Marinkovic, J. Serb. Chem. Soc., 73, 891 (2008),

15. S. Young Ly, Bioelectrochemistry, 68, 227 (2006).

16. R.E. Sabzi, K. Rezapour and N. Samadi, J. Serb. Chem. Soc., 75, 537 (2010).

17. M. O'Connell, P. Poul, L. Ericson, C. Huffman, Y. Wang, E. Haroz, C. Kuper, J. Tour, D. Ausman and R. Smalley, Chem. Phys. Lett., 342, 265 (2001)

18. K. Wang, H. Yang, L. Zhu, J. Liao, T. Lu, W. Xing, S. Xing and Q. Lv, J. Mol. Catal. B: Enzym., 58, 194 (2009).

19. B. Ge, Y. Tan, Q. Xie, M. Ma and S. Yao, Sens. Actuators B, 137, 547 (2009).

20. Y. Cheng, Y. Liu, J. Huang, Y. Xian, W. Zhang, Z. Zhang and L. Jin, Talanta, 75, 167 (2008).

21. W. Ma and D. Tian, Bioelectrochemistry, 78, 106 (2010).

22. W.S. Huang, C.H. Yang and S.H. Zhang, Anal. Bioanal. Chem., 75, 703 (2003)

23. H.S. Wang, T.H. Li, W.L. Jia and H.Y. Xu, Biosens. Bioelectron., 22, 664 (2006).

24. K. Lee, J.W. Lee, S.I. Kim and B.K. Ju, Carbon, 49, 787 (2011).

25. S. Shahrokhian and H.R.Z.-Mehrjardi, Electroanalysis, 19, 2234 (2007).

26. M.D. Rubianes and G.A. Rivas, Electrochem. Commun., 9, 480 (2007).

27. L. Fernández and H. Carrero, Electrochim. Acta, 50, 1233 (2005).

28. M. Sharp, M. Petersson and K. Edstrom, J. Electroanal. Chem., 95, 123 (1979)

29. A.A. Izuagie and F.O. Izuagie, J. Agric. Biol. Sci., 3, 367 (2007).

30. J.C. Miller and J.N. Miller, Statistics for Analytical Chemistry, John Wiley \& Sons, New York, edn. 2, p. 58 (1988). 